\title{
STRESS-STRAIN DISTRIBUTION IN THE MODEL OF RETROCALCANEAL BURSITIS BY USING HEEL-ELEVATION INSOLES
}

\author{
Bohdan Gerasimyuk \\ Department of Orthopedics and Traumatology No. $1^{1}$ \\ Igor Lazarev \\ Biomechanics Laboratory ${ }^{2}$ \\ Oleksandr Movchan \\ Department of Orthopedics and Traumatology No. $1^{1}$ \\ Maksym Skyban \\ Biomechanics Laboratory ${ }^{2}$ \\ ${ }^{1}$ Shupyk National Medical Academy of Postgraduate Education \\ 9 Dorohozhytska str., Kyiv, Ukraine, 04112 \\ ${ }^{2}$ Institute of Traumatology and Orthopedics of the National Academy \\ of Medical Sciences of Ukraine \\ 27 Bulvarno-Kudriavska str., Kyiv, Ukraine, 01601
}

\begin{abstract}
The aim of this study is the analysis of the equivalent stress on the rear foot structures in retrocalcaneal bursitis, when using heel-elevation insoles of different heights $(10 \mathrm{~mm}$ and $20 \mathrm{~mm})$.

Methods - mathematical calculations of the Achilles force required in the heel-off of the gait stance phase in the conditions of lifting the heel by $10 \mathrm{~mm}$ and $20 \mathrm{~mm}$. A 3D-simulation foot model with an enlarged retrocalcaneal bursa was created. The analysis was carried out by the finite element method to calculate and study the stress and strain in the rear foot structures.

Results. When using a $10.0 \mathrm{~mm}$ height heel-elevation insole, the calf muscle strength, which must be applied to the heel-off of the gait stance phase, was $19.0 \%$ less than without support and $26.8 \%$ less in $20.0 \mathrm{~mm}$ insole. Accordingly, analyzing the simulation results in terms of von-Mises stress, the maximum stress observed on the Achilles tendon decreases by $20.0 \%$ and by $30.0 \%$. The total deformations maximum in the model when using heel-elevation insoles decreased up to $18.1 \%$ and they were localized not in the tendon, but in the bone structures of subtalar joint.

The maximum values of the total deformation of the model in the case of $10.0 \mathrm{~mm}$ and $20.0 \mathrm{~mm}$ heel-elevation insoles were $91.67 \mathrm{~mm}(-20.2 \%)$ and $80.04 \mathrm{~mm}(-30.3 \%)$, respectively, compared $114.92 \mathrm{~mm}$ in the absence of insoles. When using insole with a height of $10.0 \mathrm{~mm}$, the stress in the retrocalcaneal bursa decreased by $20.0 \%$ and was equal to $14.92 \mathrm{MPa}$ compared to $18.66 \mathrm{MPa}$, and when using a $20.0 \mathrm{~mm}$ insoles - by $30.0 \%$.
\end{abstract}

Conclusions. It was found that when using 10.0-20.0 $\mathrm{mm}$ heel-elevation insoles, the stress distribution in the rear foot structures was significantly reduced by an average of 20.0-30.0\% and correlated with the height of the insoles.

Keywords: Achilles tendon, retrocalcaneal bursitis, tendinopathy, heel elevation insoles.

DOI: $10.21303 / 2504-5679.2020 .001444$

\section{Introduction}

Despite the large number of scientific studies, the problem of diagnosis and treatment of diseases of the Achilles tendon (AT) and surrounding structures remains relevant. A special place is occupied by the problem of treatment of AT diseases - tendinopathies and tendinitis. It is believed that the cause of these diseases is a constant overload on the tendon, which leads to inflammatory and subsequently to degenerative changes in tendon tissue. However, there are studies that show a link between the inflammatory process in the retrocalcaneal bursa and concomitant changes in the AT. According to Pavlov H. and others [1] in 9 out of 10 cases of Haglund's syndrome, retrocalcaneal bursitis (RB) and tendinitis were diagnosed. In their study, Karjalainen, P. T., Soila, K. et al., found that in 118 ATs diagnosed by magnetic resonance imaging, $19 \%$ of the cases had enlarged 
retrocalcaneal bursa. It was also found that in 15 of 18 cases of insertional tendinopathy, RB was detected [2]. Todd A. Irwin in his study [3] also points to the link between an inflammatory process in the synovial bursa and degenerative changes in the tendon itself and between RB and concomitant tendinopathy. A retrospective study [4] of 176 patients with insertional tendinopathy of AT found that $74 \%$ of patients were also diagnosed with superficial and retrocalcaneal bursitis, as well as Haglund syndrome. In our study [5] of the stress-strain state of the rear-foot structures in patients with retrocalcaneal/Haglund syndrome when standing and in the act of walking, it was proven that the maximum stress in all the rearfoot structures, regardless of the position of the foot and the ankle joint is concentrated on the AT. However, in cases of retrocalcaneal bursitis and Haglund syndrome, the stress values were significantly higher - by $10.1 \%$ and $68.6 \%$, respectively, compared to normal values. The maximum values of stress on the AT were recorded in the dorsiflexion of the foot. It was also noted that in the model with Haglund syndrome, the values of stress on the AT remained higher compared to normal values in all positions of the foot. In conclusion, it can be argued that in RB and Haglund syndrome there are prerequisites for the development of secondary tendinopathy of the AT. Timely treatment of these diseases avoids the development of changes in the AT. Therefore, in the treatment, complex measures are needed to reduce the load on the AT.

In the conservative treatment of tendinopathy, it has been suggested to use heel elevation insoles, which, by raising the heel, presumably reduce the load on the AT [6]. However, scientific works indicate controversial results: raising the heel by $15-18 \mathrm{~mm}$ increases [7], decreases [8] or does not affect $[9,10]$ the load on the AT during walking. We have not found any work that describes the effectiveness of heel elevation insoles in the treatment of patients with RB or Haglund syndrome.

According to a few authors, the use of orthopedic insoles does not reduce the risk of exacerbations and in fact has no therapeutic effect [11]. However, in some works [12] the authors used high-heeled shoes $(3-5 \mathrm{~cm})$ in the postoperative period in Haglund syndrome in order to reduce pain. However, they do not justify the reason for choosing such a height of the heel and do not indicate the duration of its use and effectiveness in reducing pain. Therefore, the study of the amount of stress on the rear-foot structures in patients with RB with the use of a heel elevation insole is relevant and answers a number of questions regarding the prevention and treatment of concomitant changes in the AT.

The aim of the study - the equivalent stress analysis of the rear foot structures in retrocalcaneal bursitis, using heel-elevation insoles of different heights $(10 \mathrm{~mm}$ and $20 \mathrm{~mm})$.

\section{Materials and methods}

At the initial stage, calculation schemes were created (Fig. 1). Mathematical calculations of the force of the calf muscle, which must be applied to the heel to push off from the plane of support in the act of walking were performed. According to the calculation scheme, depending on the height of the insoles, the center of mass of the body is shifted forward by the distance AC with a simultaneous change to the «angle of attack» $\alpha$ and the tensile force $\mathrm{F}$ of the Achilles tendon.

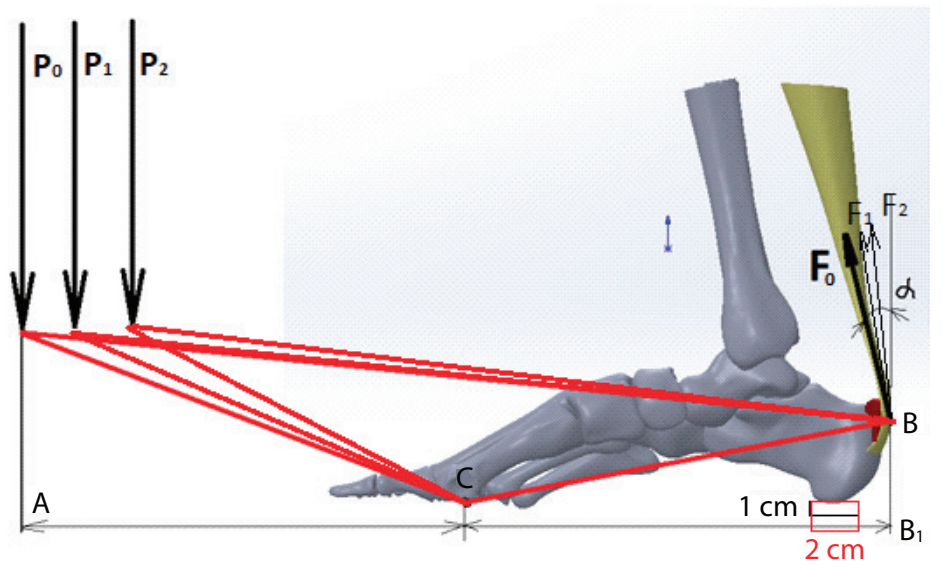

Fig. 1. Calculation diagram 
Mathematical calculations are presented in Formula 1, where $\alpha$ is the inclination angle of AT; $P$ - human weight $750 \mathrm{H}(75 \mathrm{~kg}) ; F$ is the tension force of the tendon.

$$
\sum M_{c}=0: F \cdot \sin \alpha \cdot C B_{1}-P \cdot C A .
$$

The calculation of the force $F$ required to stabilize the ankle joint in the vertical position of the body when pushing the hind leg from the area of support (dorsiflexion $+10^{\circ}$ ) was made according to Formula 2.

$$
F=\frac{P \cdot C A}{\sin \alpha \cdot C B_{1}} .
$$

The obtained data was used in further calculations by the method of finite element analysis (FEA).

In the next step, a three-dimensional simulation model of the tibia and rear foot was generated using the SolidWorks software package (Dassault Systèmes SolidWorks Corporation, Canada). Anatomical, anthropometric and CT data was used to create the model. To determine the geometric characteristics of the AT, the average anthropometric data of a person with a normosthenic posture, approximate body weight $70-75 \mathrm{~kg}$, height $170-176 \mathrm{~cm}$ were used. AT was schematically divided into the following areas (Fig. 2):

- heel bump;

- upper edge of the calcaneus;

- middle part of the AT;

- transition of the AT to the soleus muscle;

- transition of the AT to the calf muscle.
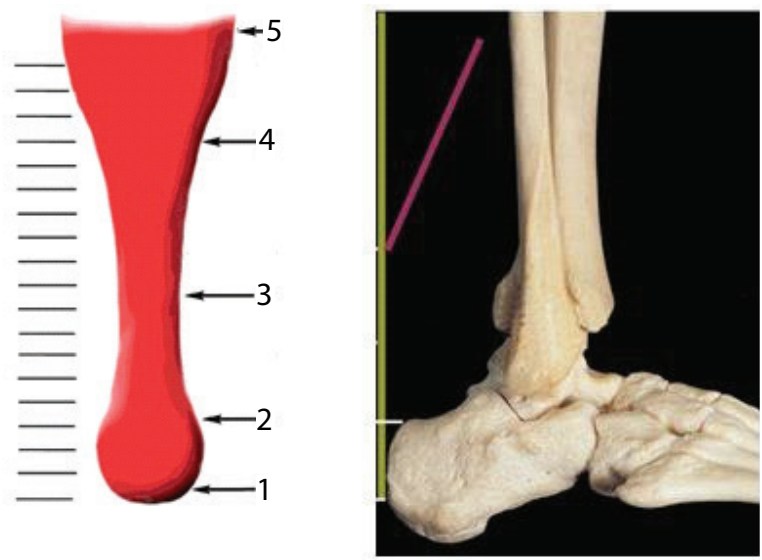

Fig. 2. Geometric characteristics of the Achilles tendon

Geometric parameters of width and thickness at each part of the AT are presented in Table $\mathbf{1 .}$

Table 1

Geometric characteristics of the Achilles tendon

\begin{tabular}{cccc}
\hline No. part & $\begin{array}{c}\text { Parts of the AT at a distance from the apex } \\
\text { of the heel bump, } \mathbf{m m}\end{array}$ & Width, mm & Thickness, mm \\
\hline 1 & 0 & 25.2 & 2.0 \\
2 & 21.0 & 19.2 & 4.5 \\
3 & 42.0 & 16.0 & 5.1 \\
4 & 64.7 & 44.6 & 6.3 \\
5 & 148.0 & 56.2 & 2.8
\end{tabular}


The boundary conditions assumed, material properties, and muscle forces applied in the model presented in Fig. 2, with a restriction on moving the heel forward and blocking rotational movements. The load applied on the ankle represented by double-support standing simulation $50 \%$ of the body weight of the average subject $75 \mathrm{~kg}, 300 \mathrm{H}$ (C) on the tibia and $75 \mathrm{H}$ (D) on the fibula. In the model all the materials were considered linear.

Further calculations performed by FEA, allows exploration of the evolution of the deformation process simulation model elements - bone, bursa and the tendon, with large nonlinear geometric and physical properties of materials and time variables and external influences. For the stress-strain analysis by the FEA, the simulation models were imported into the «ANSYS» (ANSYS, Inc., USA). The following physical properties of biological tissues used (Table 2).

Table 2

Material properties of biological tissues

\begin{tabular}{ccc}
\hline Material & Young's module, Pa & Poisson's ratio \\
\hline Cortical bone & $17.6 \mathrm{e} 9$ & 0.3 \\
Cancellous bone & $5.0 \mathrm{e} 8$ & 0.28 \\
Bursa & $5 \mathrm{e} 7$ & 0.45 \\
Tendon & $4 \mathrm{e} 8$ & 0.45
\end{tabular}

The finite element (FE) models were generated in semiautomatic mode (Fig. 3, 4) and were represented mainly by tetrahedral elements, consisted of 381574 nodes and 223604 elements. The FE mesh size of the basic model does not exceed $1 \mathrm{~mm}$. To increase the accuracy of FEA, the mesh is compacted in the contact areas of the bursa and tendon elements with FE mesh size $0.1-0.5 \mathrm{~mm}$.

The calculations were performed for different heel elevation positions $-0,10 \mathrm{~mm}$ and $20 \mathrm{~mm}$ at the heel-off of the gait stance phase, from which the maximum stress takes place.

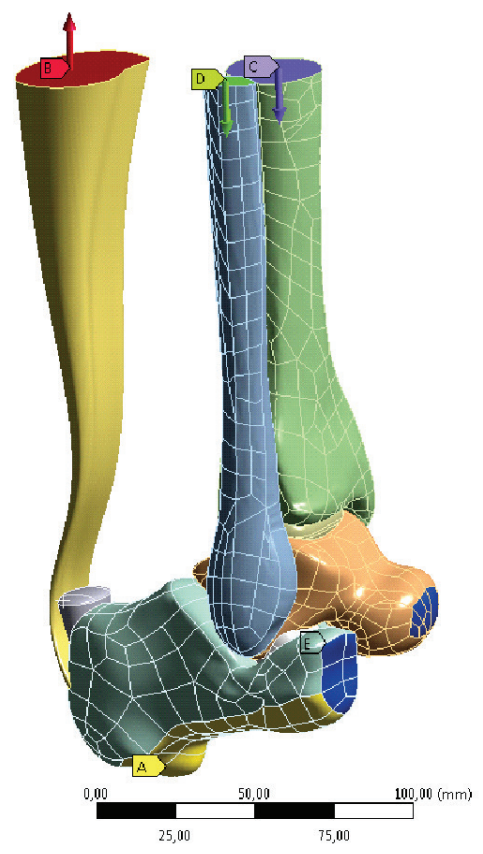

Fig. 3. Boundary conditions:

$\mathrm{A}$ - rigid fixation of the plantar area of the calcaneus; $\mathrm{B}$ - restriction of movement on the axes with the possibility of rotation (to simulate a solid foot); $\mathrm{C}-\mathrm{AT}$ tension force; $\mathrm{D}$ and $\mathrm{E}$ - body weight is applied to the tibia (90\%) and fibula (10\%) 


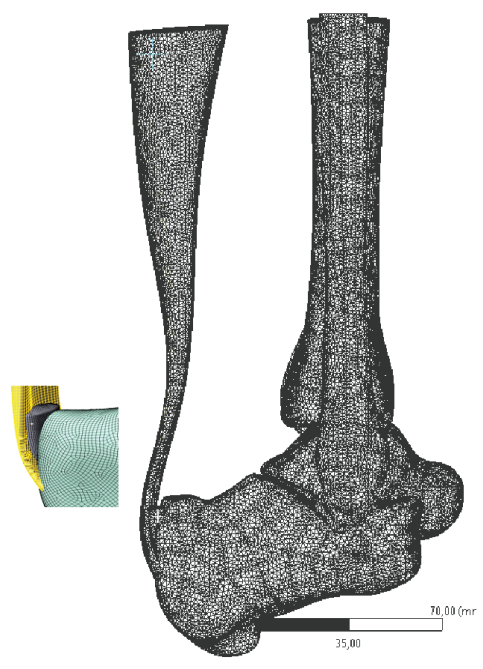

Fig. 4. FE mesh

\section{Results}

According to the results of analytical calculations, the AT tensile force depending on the heel elevation is obtained: $1028 \mathrm{H}$ - normal position; $833 \mathrm{H}$ - heel elevation height $10.0 \mathrm{~mm}$; $752 \mathrm{H}$ - heel elevation height $20.0 \mathrm{~mm}$.

From the obtained data, it is noted that the strength of the calf muscle, which must be applied to the heel to push off the ground in walking varies depending to the heel elevating position. Thus, $10.0 \mathrm{~mm}$ height heel insoles reduce the AT tensile force by $19.0 \%(833 \mathrm{H}$ vs. $1028 \mathrm{H})$ compared to the heel normal position and reduces by $26.8 \%(752 \mathrm{H}$ vs. $1028 \mathrm{H})$ by using $20.0 \mathrm{~mm}$ height heel insoles.

Stress-strain distribution in the rear foot structures in different biomechanical conditions are presented in Fig. 5, 6.

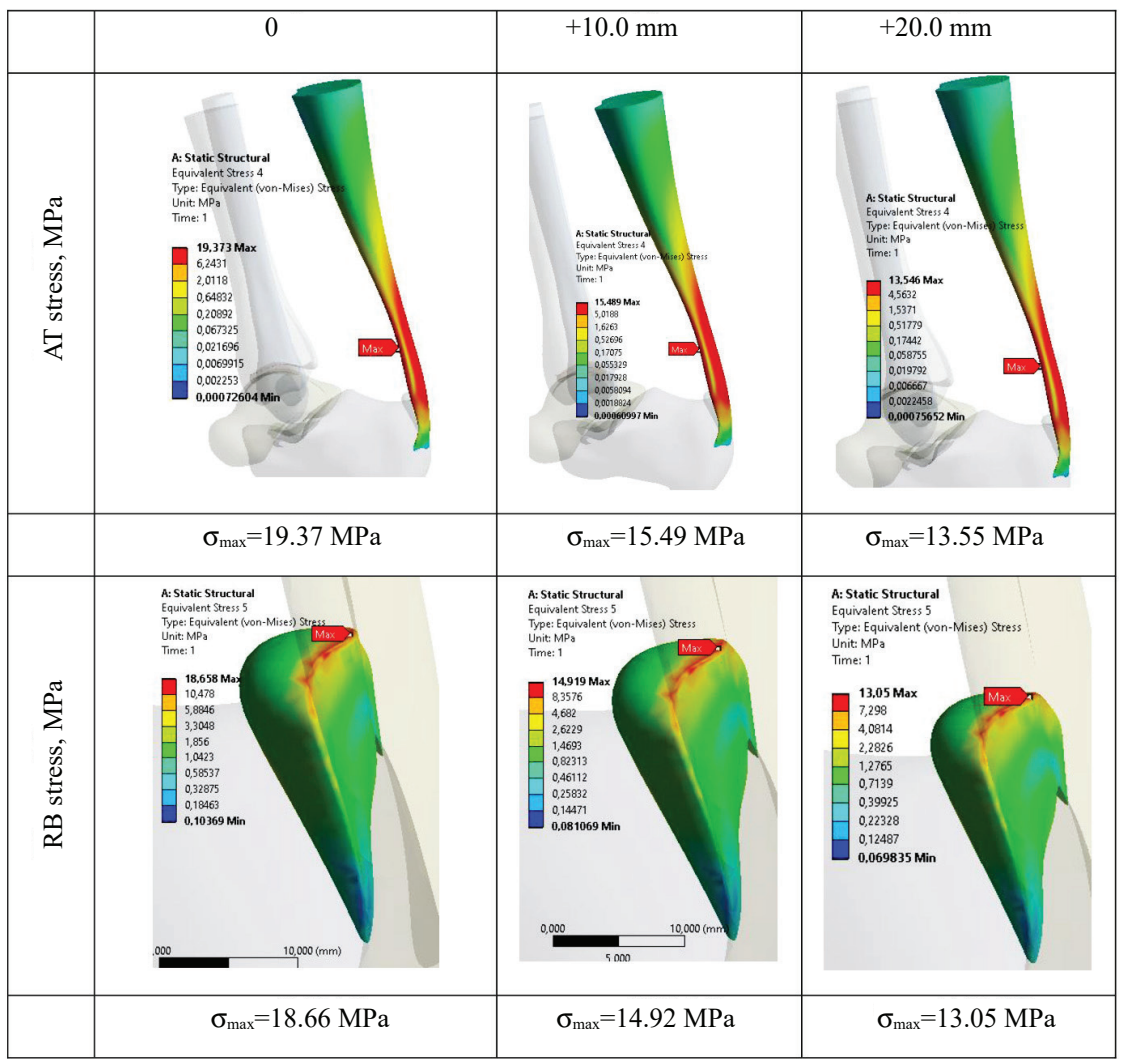

Fig. 5. Stress-strain distribution in the rear foot structures in different biomechanical conditions 


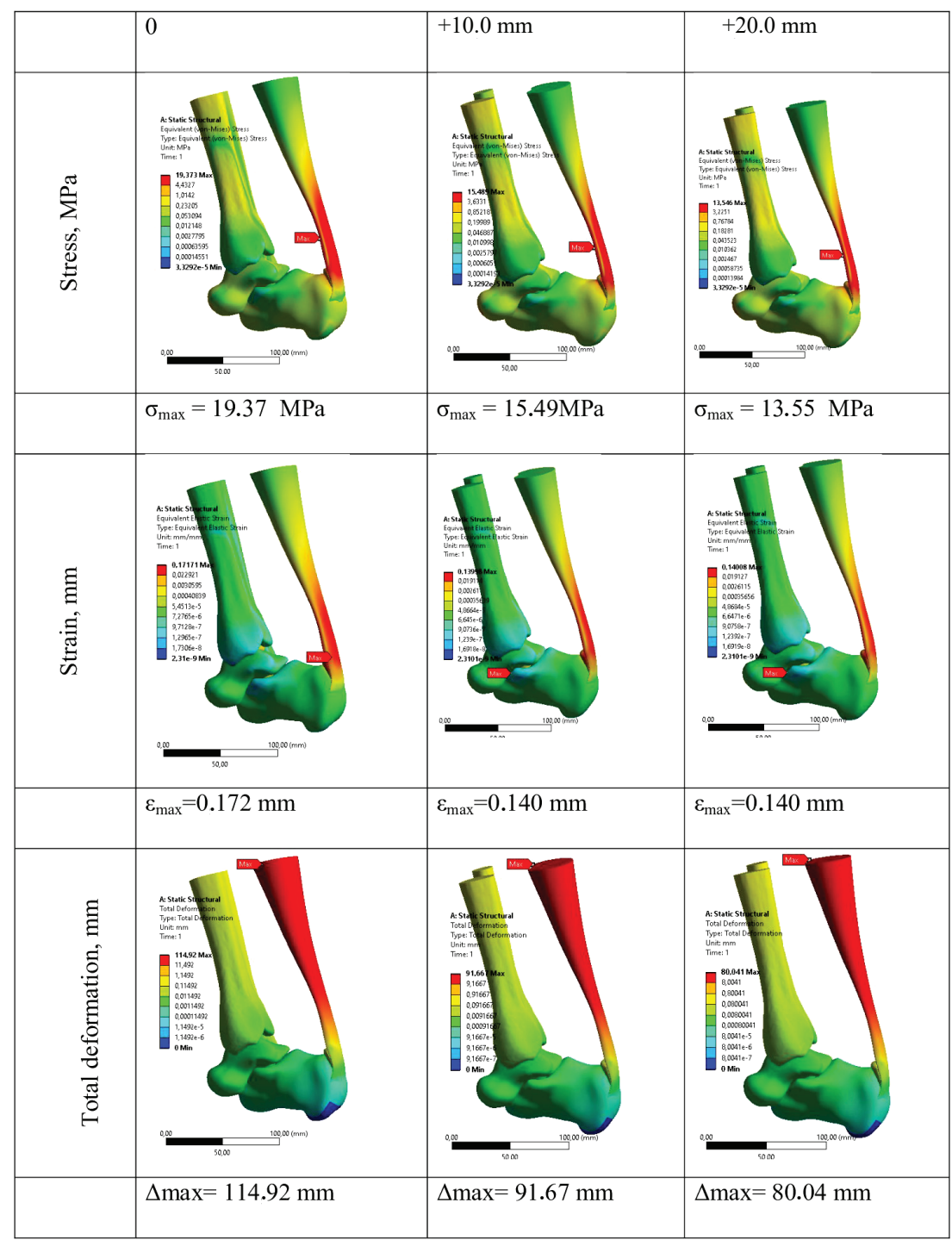

Fig. 6. Stress-strain distribution in the rear foot structures in different biomechanical conditions

According to the obtained results, it was proven that the use of heel-elevation insoles reliably and effectively reduces the stress in the retrocalcaneal bursa and AT (Fig. 7.). Thus, when the heel elevated by $10.0 \mathrm{~mm}$, the stress in the AT decreased by $20.0 \%$ (15.49 MPa vs. 19.37 MPa). When the heel is elevated by $20.0 \mathrm{~mm}$, the stress in the AT decreased by $30.0 \%$ (13.55 MPa vs. 19.37 MPa). It should be noted that the maximum stress of the whole model are located in the AT. In our opinion, reducing the load on the tendon can have a positive effect on the disease.

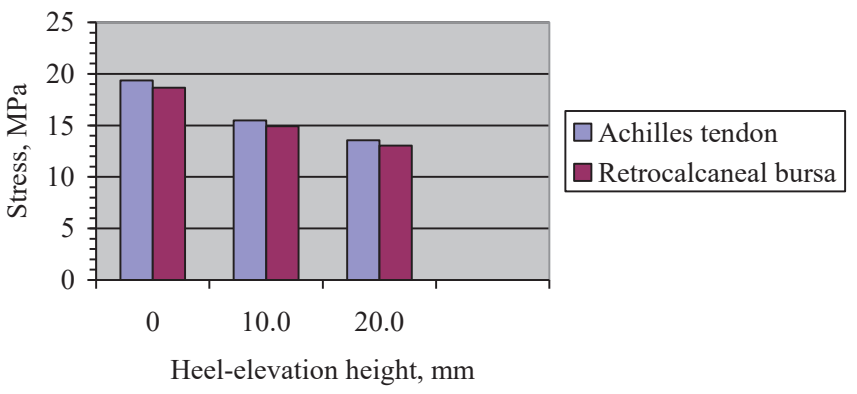

Fig. 7. Dynamics of stress change in the AT and retrocalcaneal bursa when using heel elevating insoles 
The maximum strain of the model tended to decreases - up to $18.1 \%(0.14 \mathrm{~mm}$ vs. $0.171 \mathrm{~mm})$ and was localized not on the AT, but on the subtalar joint area.

The maximum values of the Total Deformations of the model were located in the calf muscle. In the $10.0 \mathrm{~mm}$ and $20.0 \mathrm{~mm}$ heel elevating, the Total Deformations was $91.67 \mathrm{~mm}(-20.2 \%)$ and $80.04 \mathrm{~mm}(-30.3 \%)$, respectively, compared to $114.92 \mathrm{~mm}$ in the normal heel position. This indicates that heel-elevation insoles reduce the load on the calf muscle by reducing the tension.

Stress in the retrocalcaneal bursa also varied. Thus, when using $10.0 \mathrm{~mm}$ height heel insoles, the stress in the bursa decreased by $20.0 \%$ (14.92 MPa vs. 18.66 MPa), and when using $20.0 \mathrm{~mm}$ height heel insoles - by $30.0 \%$ (13.05 MPa vs. $18.66 \mathrm{~mm})$.

\section{Discussion}

The current study aimed to analyze the equivalent stress on the rear foot structures in retrocalcaneal bursitis, when using heel-elevation insoles of different heights (10 $\mathrm{mm}$ and $20 \mathrm{~mm})$. One of the causes of posterior heel pain is impingement of the retrocalcaneal bursa between the postero-superior part of the calcaneus (an increase of this part is called «Haglund's deformity») and AT. An increase in the retrocalcaneal bursa, its thight and an increase in pressure inside it directly indicate bursitis [12]. The enlargement and thight of the bursa leads to a local overload of the AT near the insertion site and the adjacent part of the calcaneus [5]. This explains the development of insertional tendinopathy in patients with retrocalcaneal bursitis [3, 4]. Therefore, one of the goals of treatment is to enlargement the retrocalcaneal recess. This can be done surgically (by removing the enlarged part of the calcaneus), or reducing the heel inclination angle, thereby increasing the angle of attack of the AT. For this, various orthopedic insoles are used.

Previous studies [13] have shown reduction of Achilles Tendon load during running by using customized arch support orthosis (CASO) or an orthotic heel lift (HL). Regarding the Achilles Tendon load, both orthoses, CASO $(p=0.003, d=0.93)$ and HL $(p=0.004, d=0.78)$, exhibited significant lower value than the control but similarly, no significant difference was noted between them in which the use of CASO yielded a slightly lower loading rate than that of HL. It should be noted that the study was conducted in healthy people who did not have tendinopathy. In another study [14] studied relative contributions of altered material properties and geometry to free AT stress distribution during a sub-maximal contraction in tendinopathic relative to healthy tendons. FEA revealed that tendinopathic tendons experience $24 \%$ less stress under the same submaximal external loading conditions compared to healthy tendons. The lower tendon stress in tendinopathy was due to a greater influence of tendon cross-sectional area, which alone reduced tendon stress by $30 \%$, compared to a lower Young's modulus, which alone increased tendon stress by $8 \%$. These findings suggest that the greater tendon cross-sectional area observed in tendinopathy compensates for the substantially lower Young's modulus, thereby protecting pathological tendon against excessive stress. However, both of these studies were devoted to the study of the pathogenetic aspects of tendinopathy.

In our study, we studied the features of load distribution on all structures of the rear foot in conditions of an enlarged retrocalcaneal bursa. FEA revealed a linear relationship between the decrease in load on all structures of the hindfoot with an increase in the height of the insole. High accuracy of the results was achieved due to the large detailing of the three-dimensional model, especially in the places of contact of the bursa with the tendon and calcaneus. In research Wulf, M. et al. [15] tensile load was calculated by measuring the propagation speed of ultrasound, which is governed by the elastic modulus and density of tendon and proportional to the tensile load to which it is exposed. This method makes it possible to obtain the results of the tensile load in the same patient, however, unlike the FEA, this method cannot visualize the distribution of the maximum load on all structures of the hindfoot.

There are several limitations to our study. Firstly, FEA does not allow to calculate absolute values of the peak load. We assumed that the AT material properties were homogeneous, which does not reflect the possibility that tendon material properties could be anisotropic [16] and thereby influence the local stress-strains, particularly in the region of the developing tendinopathy [17]. However as the spatial variations of Achilles tendon material properties are as yet unknown, and may even be homogenous in tendinopathy [18], this assumption seemed justified in the first instance. Secondly, 
although we were able to match global strains from our model to experimental data, validation of local strain estimates remains challenging [19]. We also assumed that the boundary force applied to our FE model could be represented by the measured ankle joint plantarflexion moment divided by the AT moment arm, which neglects the effects of antagonistic co-contraction and assumes the calculated force is fully transmitted to the AT. Future studies may need to include subject-specific estimates of AT moment arm which may also be assessed using freehand three-dimensional ultrasound [20] and include more detailed muscle force representations via musculoskeletal modelling approaches $[21,22]$. The effect of more detailed representation of tendon microstructure including tendon tissue architecture and tendon twist [23, 24], as well as the effect of calcaneal rotation [25], may also need to be included in future models. It is also conceivable that such models could operate in near real-time and help guide tendon training programs that seek to use targeted mechanical loading as a way of optimizing training adaptation [26, 27]. However, even at this stage, the FEA revealed an inverse relationship between the stress on the tendon and the height of the heel elevation.

\section{Conclusions}

1. Investigation of the stress-strain state of the rear foot structures by FEA makes it possible to study not only the averaged absolute values of stress, but also its distribution on different structures.

2. In this study, the effect of 10.0-20.0 mm height heel insoles on the stress distribution in the rear foot structures in retrocalcaneal bursitis was determined using computer simulations. It revealed a linear relationship between the decrease in stress on all rear foot structures with an increase in the height of the insole.

3. It was found that when using heel elevation insoles, the stress-strain distribution in different structures was significantly reduced by an average of $20.0-30.0 \%$.

4. According to the results of the study, we consider it appropriate to include the use of heelelevation insoles with $10-20 \mathrm{~mm}$ height to the retrocalcaneal bursitis treatment program. This will achieves a fast pain reduction and prevents secondary degenerative changes in the AT due to overload.

\section{Conflict of interests}

The authors declare that they have no conflicts of interest.

\section{References}

[1] Pavlov, H., Heneghan, M. A., Hersh, A., Goldman, A. B., Vigorita, V. (1982). The Haglund syndrome: initial and differential diagnosis. Radiology, 144 (1), 83-88. doi: http://doi.org/10.1148/radiology.144.1.7089270

[2] Karjalainen, P. T., Soila, K., Aronen, H. J., Pihlajamäki, H. K., Tynninen, O., Paavonen, T., Tirman, P. F. J. (2000). MR Imaging of Overuse Injuries of the Achilles Tendon. American Journal of Roentgenology, 175 (1), 251-260. doi: http://doi.org/10.2214/ ajr.175.1.1750251

[3] Irwin, T. A. (2010). Current Concepts Review: Insertional Achilles Tendinopathy. Foot \& Ankle International, 31 (10), $933-939$. doi: http://doi.org/10.3113/fai.2010.0933

[4] Alfredson, H., \& Spang, C. (2018). Clinical presentation and surgical management of chronic Achilles tendon disorders A retrospective observation on a set of consecutive patients being operated by the same orthopedic surgeon. Foot and Ankle Surgery, 24 (6), 490-494. doi: http://doi.org/10.1016/j.fas.2017.05.011

[5] Lazarev, I. A., Herasimyuk, B. S., Movchan, O. S., Skiban, M. V. (2019). Biomechanical analysis of the behavior of the rearfoot structures with retrocalcaneal bursitis and Haglund's syndrome in walking. TRAUMA, 20 (6), 12-20. doi: http://doi.org/ 10.22141/1608-1706.6.20.2019.186030

[6] Calder, J. (2012). Disorders of the Achilles Tendon Insertion: Current Concepts. Guildford: DJO Publications, 218.

[7] Dixon, S. J., Kerwin, D. G. (1998). The Influence of Heel Lift Manipulation on Achilles Tendon Loading in Running. Journal of Applied Biomechanics, 14 (4), 374-389. doi: http://doi.org/10.1123/jab.14.4.374

[8] Farris, D. J., Buckeridge, E., Trewartha, G., McGuigan, M. P. (2012). The Effects of Orthotic Heel Lifts on Achilles Tendon Force and Strain During Running. Journal of Applied Biomechanics, 28 (5), 511-519. doi: http://doi.org/10.1123/jab.28.5.511

[9] Braunstein, B., Arampatzis, A., Eysel, P., Brüggemann, G.-P. (2010). Footwear affects the gearing at the ankle and knee joints during running. Journal of Biomechanics, 43 (11), 2120-2125. doi: http://doi.org/10.1016/j.jbiomech.2010.04.001

[10] Dixon, S. J., Kerwin, D. G. (2002). Variations in Achilles Tendon Loading with Heel Lift Intervention in Heel-Toe Runners. Journal of Applied Biomechanics, 18 (4), 321-331. doi: http://doi.org/10.1123/jab.18.4.321 
[11] Mattila, V. M., Sillanpää, P. J., Salo, T., Laine, H.-J., Mäenpää, H., \& Pihlajamäki, H. (2010). Can orthotic insoles prevent lower limb overuse injuries? A randomized-controlled trial of 228 subjects. Scandinavian Journal of Medicine \& Science in Sports, 21 (6), 804-808. doi: http://doi.org/10.1111/j.1600-0838.2010.01116.x

[12] Lohrer, H., Nauck, T. (2014). Retrocalcaneal bursitis but not Achilles tendinopathy is characterized by increased pressure in the retrocalcaneal bursa. Clinical Biomechanics, 29 (3), 283-288. doi: http://doi.org/10.1016/j.clinbiomech.2013.12.002

[13] Lee, K. K. W., Ling, S. K. K., Yung, P. S. H. (2019). Controlled trial to compare the Achilles tendon load during running in flatfeet participants using a customized arch support orthoses vs an orthotic heel lift. BMC Musculoskeletal Disorders, 20 (1). doi: http://doi.org/10.1186/s12891-019-2898-0

[14] Shim, V. B., Hansen, W., Newsham-West, R., Nuri, L., Obst, S., Pizzolato, C. et. al. (2019). Influence of altered geometry and material properties on tissue stress distribution under load in tendinopathic Achilles tendons - A subject-specific finite element analysis. Journal of Biomechanics, 82, 142-148. doi: http://doi.org/10.1016/j.jbiomech.2018.10.027

[15] Wulf, M., Wearing, S. C., Hooper, S. L., Bartold, S., Reed, L., Brauner, T. (2016). The Effect of an In-shoe Orthotic Heel Lift on Loading of the Achilles Tendon During Shod Walking. Journal of Orthopaedic \& Sports Physical Therapy, 46 (2), $79-86$. doi: http://doi.org/10.2519/jospt.2016.6030

[16] Bogaerts, S., Desmet, H., Slagmolen, P., Peers, K. (2016). Strain mapping in the Achilles tendon - A systematic review. Journal of Biomechanics, 49 (9), 1411-1419. doi: http://doi.org/10.1016/j.jbiomech.2016.02.057

[17] Chatzistergos, P., Maganaris, C., Chockalingam, N. (2016). Sensitivity of a numerical model to detect regional differences in mechanical properties of tendons. Foot and Ankle Surgery, 22 (2), 15. doi: http://doi.org/10.1016/j.fas.2016.05.024

[18] Choi, R. K., Smith, M. M., Martin, J. H., Clarke, J. L., Dart, A. J., Little, C. B., Clarke, E. C. (2016). Chondroitin sulphate glycosaminoglycans contribute to widespread inferior biomechanics in tendon after focal injury. Journal of Biomechanics, 49 (13), 2694-2701. doi: http://doi.org/10.1016/j.jbiomech.2016.06.006

[19] Maganaris, C. N., Chatzistergos, P., Reeves, N. D., Narici, M. V. (2017). Quantification of Internal Stress-Strain Fields in Human Tendon: Unraveling the Mechanisms that Underlie Regional Tendon Adaptations and Mal-Adaptations to Mechanical Loading and the Effectiveness of Therapeutic Eccentric Exercise. Frontiers in Physiology, 8. doi: http://doi.org/ 10.3389/fphys.2017.00091

[20] Obst, S. J., Barber, L., Miller, A., Barrett, R. S. (2017). Reliability of Achilles Tendon Moment Arm Measured In Vivo Using Freehand Three-Dimensional Ultrasound. Journal of Applied Biomechanics, 33 (4), 300-304. doi: http://doi.org/ 10.1123/jab.2016-0261

[21] Pizzolato, C., Lloyd, D. G., Sartori, M., Ceseracciu, E., Besier, T. F., Fregly, B. J., Reggiani, M. (2015). CEINMS: A toolbox to investigate the influence of different neural control solutions on the prediction of muscle excitation and joint moments during dynamic motor tasks. Journal of Biomechanics, 48 (14), 3929-3936. doi: http://doi.org/10.1016/j.jbiomech.2015.09.021

[22] Pizzolato, C., Reggiani, M., Modenese, L., Lloyd, D. G. (2016). Real-time inverse kinematics and inverse dynamics for lower limb applications using OpenSim. Computer Methods in Biomechanics and Biomedical Engineering, 20 (4), $436-445$. doi: http://doi.org/10.1080/10255842.2016.1240789

[23] Pękala, P. A., Henry, B. M., Ochała, A., Kopacz, P., Tatoń, G., Młyniec, A. et. al. (2017). The twisted structure of the Achilles tendon unraveled: A detailed quantitative and qualitative anatomical investigation. Scandinavian Journal of Medicine \& Science in Sports, 27 (12), 1705-1715. doi: http://doi.org/10.1111/sms.12835

[24] Shim, V. B., Handsfield, G. G., Fernandez, J. W., Lloyd, D. G., Besier, T. F. (2018). Combining in silico and in vitro experiments to characterize the role of fascicle twist in the Achilles tendon. Scientific Reports, 8 (1). doi: http://doi.org/10.1038/ s41598-018-31587-z

[25] Lersch, C., Grötsch, A., Segesser, B., Koebke, J., Brüggemann, G.-P., Potthast, W. (2012). Influence of calcaneus angle and muscle forces on strain distribution in the human Achilles tendon. Clinical Biomechanics, 27 (9), 955-961. doi: http://doi.org/ 10.1016/j.clinbiomech.2012.07.001

[26] Pizzolato, C., Lloyd, D. G., Barrett, R. S., Cook, J. L., Zheng, M. H., Besier, T. F., Saxby, D. J. (2017). Bioinspired Technologies to Connect Musculoskeletal Mechanobiology to the Person for Training and Rehabilitation. Frontiers in Computational Neuroscience, 11. doi: http://doi.org/10.3389/fncom.2017.00096

[27] Pizzolato, C., Reggiani, M., Saxby, D. J., Ceseracciu, E., Modenese, L., Lloyd, D. G. (2017). Biofeedback for Gait Retraining Based on Real-Time Estimation of Tibiofemoral Joint Contact Forces. IEEE Transactions on Neural Systems and Rehabilitation Engineering, 25 (9), 1612-1621. doi: http://doi.org/10.1109/tnsre.2017.2683488 